\title{
The Establishment of Objective Performance Evaluation System for PPP Project Considering the Influence of Factors between Indicators
}

\author{
Xuyi Zhang ${ }^{1}$ and Jihkuang Chen ${ }^{2, b}$ * \\ ${ }^{1,2}$ School of Management, Xiamen University Tan Kah Kee College \\ b*pony1146@163.com
}

Keywords: PPP Project; Entropy Method; DEMATEL

\begin{abstract}
The construction of public infrastructure and public affairs management requires a lot of capital investment, which will lead to excessive financial burden on the government. Therefore, the Public-Private Partnership (PPP) is increasingly being introduced into public construction and operations. In the past related research, most of the PPP project performance indicators based on key performance indicators or balanced scorecards were in line with the life cycle of PPP projects, then estimated the importance of indicators through methods such as AHP (Analytic Hierarchy Process) or factor analysis, however it lacks objectivity and ignores the interaction between indicators. This paper quotes the DEMATEL method to analyze the influence between indicators, and further integrates and corrects the final weights to establish a relatively complete PPP performance evaluation system.
\end{abstract}

\section{Introduction}

In recent years, most countries attach great importance to the construction of public infrastructure and public affairs management, but this requires a lot of capital investment, which will lead to excessive financial burden on the government. Therefore, the Public-Private Partnership (PPP) is increasingly being introduced into public construction and operations, which can effectively reduce the financial and administrative burden of government departments, and can also increase the quantity, quality, and efficiency of public construction.

With the extensive application and problems that followed by PPP model, it is of great significance to implement reasonable and effective performance evaluation for PPP projects. In the past related research, most of the PPP project performance indicators based on key performance indicators or balanced scorecards were in line with the life cycle of PPP projects [1], then estimated the importance of indicators through methods such as AHP (Analytic Hierarchy Process) or factor analysis [2-3].

Although AHP takes into account the comparative relationship between indicators, it lacks objectivity. Although factor analysis is a more objective analysis method, it ignores the interaction between indicators. Therefore, based on the four dimensions of balanced scorecard, this paper establishes the evaluation index system on PPP project performance from the financial dimension, customer dimension, internal business process dimension, and learning and growth dimension. According to the characteristics of PPP project, related research and actual research, this paper extends the customer dimension to the stakeholder dimension and introduces a more objective entropy method to analyze the weight of the indicator. At the same time, this paper quotes the DEMATEL method to analyze the influence between indicators, and further integrates and corrects the final weights to establish a relatively complete PPP performance evaluation system.

\section{Method}

Entropy Method. Entropy method is an objective weighting method to calculate information entropy through the uncertainty of data. This method has been widely used by scholars [4-5]. Entropy method is a decision method which can measure the amount of useful information provided by the obtained data. First, it needs to standardize the actual data and obtain a standardized matrix. Let multi-attribute decision-making have $m$ evaluation objects, $n$ evaluation indicators, $x_{i j}$ is the $j$-th evaluation index value of the $i$-th object. 
(1) Assuming that there are $m$ evaluated objects and $n$ evaluation indexes for each evaluated object, a judgment matrix is constructed:

$$
\mathrm{X}=\left(X_{i j}\right)_{m \times n}(\mathrm{i}=1,2, \ldots . ., \mathrm{m} ; \mathrm{j}=1,2, \ldots . \mathrm{n})
$$

(2) Standardize the judgment matrix:

$$
p_{i j}=X_{i j} / \sum X_{i j}
$$

(3) Calculate information entropy:

(4) Calculate index deviation:

$$
E_{j}=-k \sum_{i=1}^{m} P_{i j} \ln P_{i j}, \text { where } \mathrm{k}=1 / \ln m
$$

(5) Define the weight of indicator j:

$$
D_{j}=1-E_{j}
$$

$$
w_{j}=D_{j} / \sum_{j=1}^{n} D_{j}
$$

DEMATEL technique. The decision making trail and evaluation laboratory (DEMATEL) [6] has been applied in many researches [7-8]: The procedure is as below:

(1) Establish direct-relation matrix

With the opinion integration of all experts, the direct-relation matrix, A, of $n \times n$ can be obtained. In the direct relation matrix, $A, x_{i j}$ represents the variable, the level of $i$ affects variable $j$, and the diagonal variable $\mathrm{x}_{\mathrm{ij}}$ of the direct-relation matrix, $\mathrm{A}$ is set to 0 .

(2) Calculate normalized direct-relation matrix

The normalized direct-relation matrixes $\mathrm{N}$ can be obtained through the maximum value of sum of the row vector in matrixes $\mathrm{A}$ as the normalized base.

(3) Calculate total-relation matrix

The total-relation matrix, T, can be obtained from Eq. (6)

$$
\mathrm{T}=\operatorname{limit}_{\mathrm{w} \rightarrow \infty}\left(N+N^{2}+\ldots . .+N^{w}\right)=N(I-N)^{-1}
$$

Combined with DEMATEL and Entropy method. In order to give consideration to the objectivity of weight and the relationship between factors, the weight calculated by entropy weight method is combined with DEMATEL method. In this study, the combined weight method proposed by Li et al. (2006) [9]. The method is used to establish the combined weights of the weight vector $\mathrm{W}$ obtained by the entropy weight method and the complete relation matrix $\mathrm{T}$ obtained by the DEMATEL method, as shown in the following equation (7):

$$
W_{f}=\alpha W+(1-\alpha)(W \times T)
$$

Where: a can be set according to the sensitivity of the study, generally taken as 0.5 .

\section{Case Study}

Design of performance evaluation indicators for PPP projects. This study attempts to combine the research of many scholars [10-11], comprehensively refers to the number and importance of indicators in the relevant research results and combined with the actual investigation of PPP projects, and has deleted unnecessary and less influential indicators. Finally, 13 PPP project performance evaluation indicators were determined by expert method. The established indicator system is shown in Table 1: 
Table 1. Index system

\begin{tabular}{cl}
\hline Finance & Return on project investment \\
& Corporate financial position \\
& Financing structure \\
& Public satisfaction index \\
Gtakeholder & Government satisfaction \\
& Private sector satisfaction \\
& Partner coordination degree \\
& Risk sharing, transfer mechanism \\
Intemal process & Quality and safety management \\
& Government supervision and efficiency \\
& Cost control \\
Learning and growth & Technology transfer capability and innovation \\
& Social contribution \\
\hline
\end{tabular}

Analysis. Seven relevant experts (including 2 government executives and 2 private sector supervisors and 3 engineering management teachers) were independently rated for their perceived importance of the indicators. The importance of each factor ranges from $1 \sim 10$, representing the range from unimportant to very important. An evaluation matrix $X_{7 \times 13}$ is abtained:

$$
\mathrm{X}=\left[\begin{array}{lllllllllllll}
8 & 3 & 9 & 4 & 5 & 6 & 5 & 7 & 4 & 5 & 4 & 8 & 4 \\
3 & 8 & 9 & 3 & 4 & 5 & 6 & 9 & 9 & 7 & 3 & 2 & 6 \\
3 & 4 & 3 & 9 & 3 & 6 & 3 & 5 & 8 & 8 & 5 & 6 & 8 \\
6 & 3 & 4 & 5 & 7 & 3 & 8 & 2 & 5 & 5 & 7 & 8 & 6 \\
2 & 9 & 7 & 4 & 5 & 7 & 5 & 4 & 9 & 4 & 7 & 4 & 6 \\
6 & 8 & 7 & 3 & 6 & 6 & 7 & 9 & 4 & 3 & 3 & 7 & 3 \\
9 & 4 & 3 & 2 & 5 & 8 & 8 & 3 & 2 & 3 & 7 & 4 & 6
\end{array}\right]
$$

The value of entropy index is calculated by the equations (1) to (3). Then, the weights of each indicator are obtained through equations (4) and (5), as shown in Table 2 below:

Table 2. Entropy method weight result

\begin{tabular}{cccccccccccccc}
\hline & P11 & P12 & P13 & P21 & P22 & P23 & P24 & P31 & P32 & P33 & P34 & P41 & P42 \\
\hline $\mathrm{E}_{\mathrm{j}}$ & 0.940 & 0.951 & 0.955 & 0.945 & 0.985 & 0.983 & 0.978 & 0.941 & 0.947 & 0.968 & 0.970 & 0.959 & 0.980 \\
$\mathrm{~d}_{\mathrm{j}}$ & 0.060 & 0.049 & 0.045 & 0.055 & 0.015 & 0.017 & 0.022 & 0.059 & 0.053 & 0.032 & 0.030 & 0.041 & 0.020 \\
$\mathrm{~W}_{\mathrm{j}}$ & 0.120 & 0.099 & 0.090 & 0.111 & 0.030 & 0.035 & 0.044 & 0.118 & 0.107 & 0.064 & 0.060 & 0.083 & 0.039 \\
\hline
\end{tabular}

In addition, 7 experts are required to assign values to the mutual influence of indicators. The degree of influence between the set indicators and the indicators is in the range of $0 \sim 3$ points, which represents "no impact" to "very large impact". After the geometric mean, the following direct relationship matrix A is obtained:

$$
A=\left[\begin{array}{ccccccccccccc}
0 & 0 & 2.43 & 0 & 1.02 & 2.73 & 0 & 2.09 & 1.89 & 0 & 0 & 0 & 0 \\
0 & 0 & 2.01 & 0 & 0.99 & 0 & 0 & 1.33 & 1.93 & 0 & 1.52 & 0 & 0 \\
2.73 & 0 & 0 & 0 & 1.32 & 1.54 & 0 & 1.93 & 0 & 0 & 0 & 0 & 0 \\
1.34 & 0 & 0 & 0 & 1.54 & 0.61 & 0 & 0 & 0 & 0 & 0 & 0 & 2.07 \\
0 & 0 & 0 & 2.11 & 0 & 0 & 0 & 0 & 0 & 2.33 & 0 & 1.93 & 1.44 \\
0 & 0 & 0 & 0 & 0 & 0 & 0 & 0 & 0 & 0 & 1.86 & 0 & 0 \\
0 & 0 & 0 & 0 & 0.73 & 0.82 & 0 & 0 & 0 & 0 & 1.25 & 0 & 0 \\
1.83 & 1.11 & 1.93 & 0 & 1.26 & 1.33 & 0 & 0 & 0 & 0 & 0 & 0 & 0 \\
1.51 & 0 & 0 & 2.63 & 2.11 & 1.76 & 0 & 0 & 0 & 0 & 1.32 & 0 & 1.57 \\
0 & 0 & 0 & 2.33 & 0.89 & 1.09 & 1.87 & 0 & 2.73 & 0 & 0.37 & 0 & 0 \\
2.59 & 1.31 & 0 & 0 & 0 & 0.68 & 1.52 & 0 & 2.46 & 0.67 & 0 & 0 & 0 \\
0 & 0 & 0 & 0 & 1.14 & 0 & 0 & 0 & 1.89 & 0 & 0 & 0 & 1.74 \\
0 & 0 & 0 & 2.54 & 1.23 & 0.51 & 0 & 0 & 0 & 30 & 0 & 2.12 & 0
\end{array}\right]
$$

And then, the direct relation matrix is normalized to obtain the initial direct influence matrix $\mathrm{N}$. Then calculate the total relation matrix $\mathrm{T}$ by equation (6), as follows: 


$T=\left[\begin{array}{lllllllllllll}0.21 & 0.05 & 0.33 & 0.17 & 0.30 & 0.46 & 0.03 & 0.30 & 0.28 & 0.07 & 0.12 & 0.08 & 0.12 \\ 0.22 & 0.05 & 0.28 & 0.18 & 0.29 & 0.21 & 0.04 & 0.22 & 0.31 & 0.08 & 0.23 & 0.08 & 0.13 \\ 0.34 & 0.04 & 0.13 & 0.11 & 0.26 & 0.32 & 0.02 & 0.27 & 0.11 & 0.06 & 0.08 & 0.06 & 0.08 \\ 0.18 & 0.01 & 0.05 & 0.14 & 0.25 & 0.15 & 0.02 & 0.04 & 0.07 & 0.06 & 0.04 & 0.10 & 0.28 \\ 0.09 & 0.01 & 0.03 & 0.38 & 0.18 & 0.12 & 0.05 & 0.02 & 0.14 & 0.26 & 0.05 & 0.27 & 0.29 \\ 0.07 & 0.03 & 0.02 & 0.03 & 0.04 & 0.05 & 0.03 & 0.02 & 0.07 & 0.02 & 0.20 & 0.01 & 0.02 \\ 0.06 & 0.02 & 0.02 & 0.05 & 0.11 & 0.12 & 0.03 & 0.02 & 0.06 & 0.03 & 0.15 & 0.03 & 0.04 \\ 0.30 & 0.13 & 0.29 & 0.11 & 0.27 & 0.30 & 0.02 & 0.12 & 0.12 & 0.06 & 0.09 & 0.06 & 0.08 \\ 0.30 & 0.03 & 0.09 & 0.45 & 0.40 & 0.35 & 0.05 & 0.08 & 0.15 & 0.10 & 0.21 & 0.13 & 0.33 \\ 0.15 & 0.02 & 0.04 & 0.41 & 0.28 & 0.27 & 0.20 & 0.04 & 0.35 & 0.07 & 0.15 & 0.08 & 0.18 \\ 0.40 & 0.15 & 0.14 & 0.20 & 0.23 & 0.31 & 0.18 & 0.12 & 0.40 & 0.12 & 0.15 & 0.07 & 0.14 \\ 0.07 & 0.01 & 0.02 & 0.17 & 0.23 & 0.09 & 0.02 & 0.02 & 0.23 & 0.05 & 0.05 & 0.09 & 0.27 \\ 0.07 & 0.01 & 0.02 & 0.35 & 0.24 & 0.12 & 0.01 & 0.02 & 0.08 & 0.05 & 0.03 & 0.27 & 0.15\end{array}\right]$

The final weight vector $W_{f}$ is obtained by equation (7), and the comparison is sorted as shown in Table 3 below:

Table 3. Final weight and ranking

\begin{tabular}{ccccc}
\hline Indexes & $\mathrm{W}$ & $\mathrm{Wt}=\mathrm{W}$ X T & $\mathrm{W}_{\mathrm{f}}$ & Order \\
\hline P11 & 0.12 & 0.214 & 0.167 & 1 \\
P12 & 0.099 & 0.046 & 0.073 & 11 \\
P13 & 0.09 & 0.144 & 0.117 & 7 \\
P21 & 0.111 & 0.206 & 0.159 & 2 \\
P22 & 0.03 & 0.262 & 0.146 & 4 \\
P23 & 0.035 & 0.253 & 0.144 & 5 \\
P24 & 0.044 & 0.049 & 0.046 & 13 \\
P31 & 0.118 & 0.123 & 0.121 & 6 \\
P32 & 0.107 & 0.189 & 0.148 & 3 \\
P33 & 0.064 & 0.074 & 0.069 & 12 \\
P34 & 0.06 & 0.121 & 0.09 & 9 \\
P41 & 0.083 & 0.092 & 0.088 & 10 \\
P42 & 0.039 & 0.17 & 0.104 & 8 \\
\hline
\end{tabular}

Result. From the results of the combined weights, the top three rankings are "Project ROI", "Public Satisfaction" and "Quality and Safety Management", and the values are 0.167, 0.159, and 0.148, respectively. The last two rankings are "Partnership Coordination" and "Government Supervision and Service Efficiency". It shows that when measuring the success of PPP projects, the key criteria are "Project ROI", "Public Satisfaction" and "Quality and Safety Management". The Project ROI is the key to the viability of the project and the main driving force for the PPP project to attract the private sector. Although the public does not participate in investment and construction, it is the payer of the project. From this perspective, the public is the main person to judge the PPP project. Quality and safety management is an important part of performance indicators in the process of project construction, and is also the basic element of project success.

\section{Conclusion}

In this paper, the objective performance evaluation system of PPP project is established by combining entropy method with DEMATEL method and considering the interaction between factors. The analysis shows that the key of PPP project performance evaluation lies in the return on investment, public satisfaction and quality and safety management, which provides a direction for the reasonable evaluation of the performance level of PPP project. However, the PPP project is a huge and complicated cooperation mode, so it needs further research to evaluate the performance index of PPP project comprehensively, objectively and systematically. For example, the PPP project performance evaluation index constructed in this study is applicable to general PPP projects, but it needs further discussion and improvement for different PPP project evaluation.

\section{References}

[1] L. Chen, Summary of Research on Performance Evaluation of PPP Projects, Fiscal Science. 2017 (04) 90-96.

[2] L. Lan, and C.X. Gao, Study on PPP Performance Evaluation System Based on AHP, Journal of Hainan University(Humanities and Social Sciences). 2013 (31) 115-119. 
[3] D.T. Nguyen, Research on Performance Evaluation Indicators and Methods of PPP Projects in Vietnam Highway Construction, Hunan University, 2017.

[4] F.X.Wang, A.H. Mao, H.L. Li, and M.X. Jia, Urbanization Quality Measurement and Spatial Difference Analysis of Shandong Province Based on Entropy Method, Geography Science. 2013 (33) 1323-1329

[5] H. Zou, W. Xu, and W. Yang, Research on Regional Innovation Capability Evaluation in China Based on Entropy Method, Science and Technology Management Research. 2013 (23) 56-61.

[6] A, Ganus, and E. Fontela, Perceptions of the world problematique: Communication procedure, communicating with those bearing collective responsibility. DEMATEL Report No. 1, Battelle Geneva Research Center, Geneva, Switzerland, 1973.

[7] X.Y. Fu, Q.H. ZHU, and J. Saekis, Evaluating green supplier development programs at a telecommunications systems provider, International Journal of Production Economics. 2012 (140) 357-367.

[8] S. Tzeng, Applying DEMATEL to Investigate the Relationship between Factors Affecting Parole Boards' Decision-Making in Taiwan, Prison Journal. 2014 (94) 118-136.

[9] H.W. Li, and D.Q. Zhou, and L. Zhang, Improvement of Analytic Hierarchy Process by Using DEMATEL Method and Cross-Reinforcement Matrix Method, Statistics and Decision. 2006 (8) $10-11$.

[10] X.B. Zhao, Research on performance evaluation of PPP project, Tsinghua University, 2009..

[11]X.J. Wu, Research on Performance Evaluation System of PPP Project, Xi'an University of Architecture and Technology, 2016. 